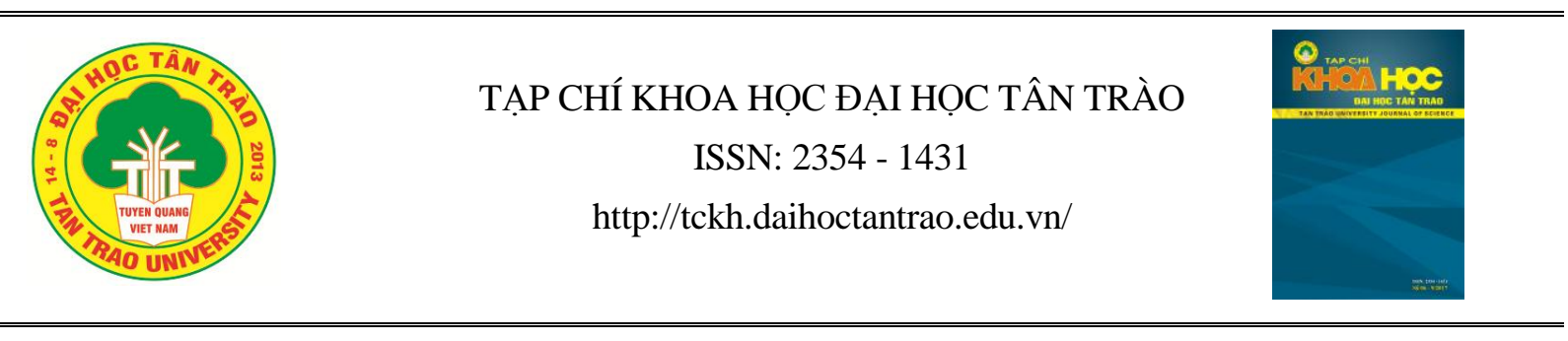

\title{
THÀNH PHẦ LOÀI ỐC CẠN (GASTROPODA: MOLLUSCA) XÃ BẢN THI VÀ XÃ XUÂN LẠC THUỘC KHU BẢO TỒN LOÀI VÀ SINH CẢNH NAM XUÂN LẠC, HUYỆN CHỢ ĐỒN, TỈNH BẮC KẠN
}

\author{
Hoàng Ngọc Khắc ${ }^{1}$, Trần Thịnh ${ }^{1}$, Nguyễn Thanh Bình ${ }^{2}$ \\ ${ }^{I}$ Truoòng Đại học Tài nguyên và Môi truờng Hà Nội \\ ${ }^{2}$ Viện nghiên cứu biển và hải đảo \\ *Email: hnkhac@hunre.edu.vn
}

\section{Thông tin bài viết}

Ngày nhận bài:

8/6/2020

Ngày duyệt đăng:

12/8/2020

Tù khóa:

Ốc cạn, Chân bụng, Xuân Lạc, Bản Thi, Chợ Đồn, Bắc Kạn.

\section{Tóm tắt}

Khu bảo tồn loài và sinh cảnh Nam Xuân Lạc, huyện Chợ Đồn, tỉnh Bắc Kạn là một trong những khu vực núi đá vôi tiêu biểu của miền Bắc Việt Nam, có rừng tự nhiên ít tác động, địa hình hiểm trở, tạo điều kiện cho nhiều loài động thực vật sinh sống. Kết quả điều tra thành phần loài ốc cạn tại các xã ở Xuân Lạc và Bản Thi thuộc Khu bảo tồn sinh cảnh Nam Xuân Lạc đã xác định được 49 loài, thuộc 34 giống, 12 họ, 4 bộ, 3 phân lớp. Trong đó, phân lớp Heterobranchia đa dạng nhất với 34 loài (chiếm 69,39\%); Bộ Stylommatophora có thành phần loài đa dạng nhất, với 33 loài (chiếm 67,35\%); họ Camaenidae có số loài nhiều nhất, với 16 loài (chiếm 32,65\%). Thành phần loài ốc cạn trong khu vực nghiên cứu có phân loại khá phong phú, phù hợp với đặc điểm chung của khu hệ ốc cạn ở miền núi phía Bắc Việt Nam, Đông Nam Á và Nam Trung Quốc. Độ đa dạng của ốc cạn khá cao, với chỉ số Shannon $\mathrm{H} "=3,5$. Kết quả nghiên cứu cũng xác định được 7 loài có giá trị kinh tế. Những loài này được người dân địa phương sử dụng làm thực phẩm. Hoạt động khai thác diễn ra nhiều nhất từ tháng 4 đến tháng 7 hàng năm. Với hoạt động khai thác mạnh như hiện nay, nguồn lợi ốc cạn sẽ ngày càng cạn kiệt, một số loài có thể bị đe dọa.

\section{MỞ ĐẦU}

Ốc cạn (Mollusca: Gastropoda) là một trong những nhóm thân mềm chân bụng sống trên cạn, có thành phần loài khá đa dạng trong hệ sinh thái trên cạn. Chúng giữ vai trò quan trọng trong nhiều hệ sinh thái. Các nghiên cứu cho thấy vùng núi đá vôi là môi trường sống thuận lợi, tập trung nhiều cả về số lượng loài cũng như số lượng cá thể ốc cạn. Khu bảo tồn loài và sinh cảnh Nam Xuân Lạc, tỉnh Bắc
Kạn nằm giữa khu bảo tồn thiên nhiên $\mathrm{Na}$ Hang và Vườn Quốc gia (VQG) Ba Bể [1], rừng tự nhiên ít bị tác động, địa hình hiểm trở đã tạo điều kiện cho nhiều loài động thực vật sinh sống, là một trong những khu vực đặc trưng vùng núi đá vôi ở miền Bắc Việt Nam. Bản Thi và Xuân Lạc là 2 xã chính nằm trong vùng đệm của Khu bảo tồn. Cho đến nay, các nghiên cứu về đa dạng sinh học động vật mới tập 
trung chủ yếu về các loài chim, thú, lưỡng cư, bò sát [4], [5], còn thiếu các dẫn liệu về nhóm ốc cạn ở khu vực này. Do vậy, nghiên cứu về thành phần loài ốc cạn ở đây sẽ góp phần quan trọng trong việc hoàn thiện dữ liệu về đa dạng sinh học tại Khu bảo tồn, cũng như dũ̃ liệu về thân mềm chân bụng trên cạn tại Việt Nam.

\section{THỜI GIAN, ĐỊA ĐIỂM, PHƯONG PHÁP NGHIÊN CÚU}

\section{1. Địa điểm và thò̀i gian nghiên cứu}

Nghiên cứu được thực hiện qua 2 đợt khảo sát thực địa vào tháng 06/2017 và tháng 8/2017, thu 35 mẫu tại 35 ô tiêu chuẩn tại Khu bảo tồn loài và sinh cảnh Nam Xuân Lạc, tỉnh Bắc Kạn (bản đồ hình 1).

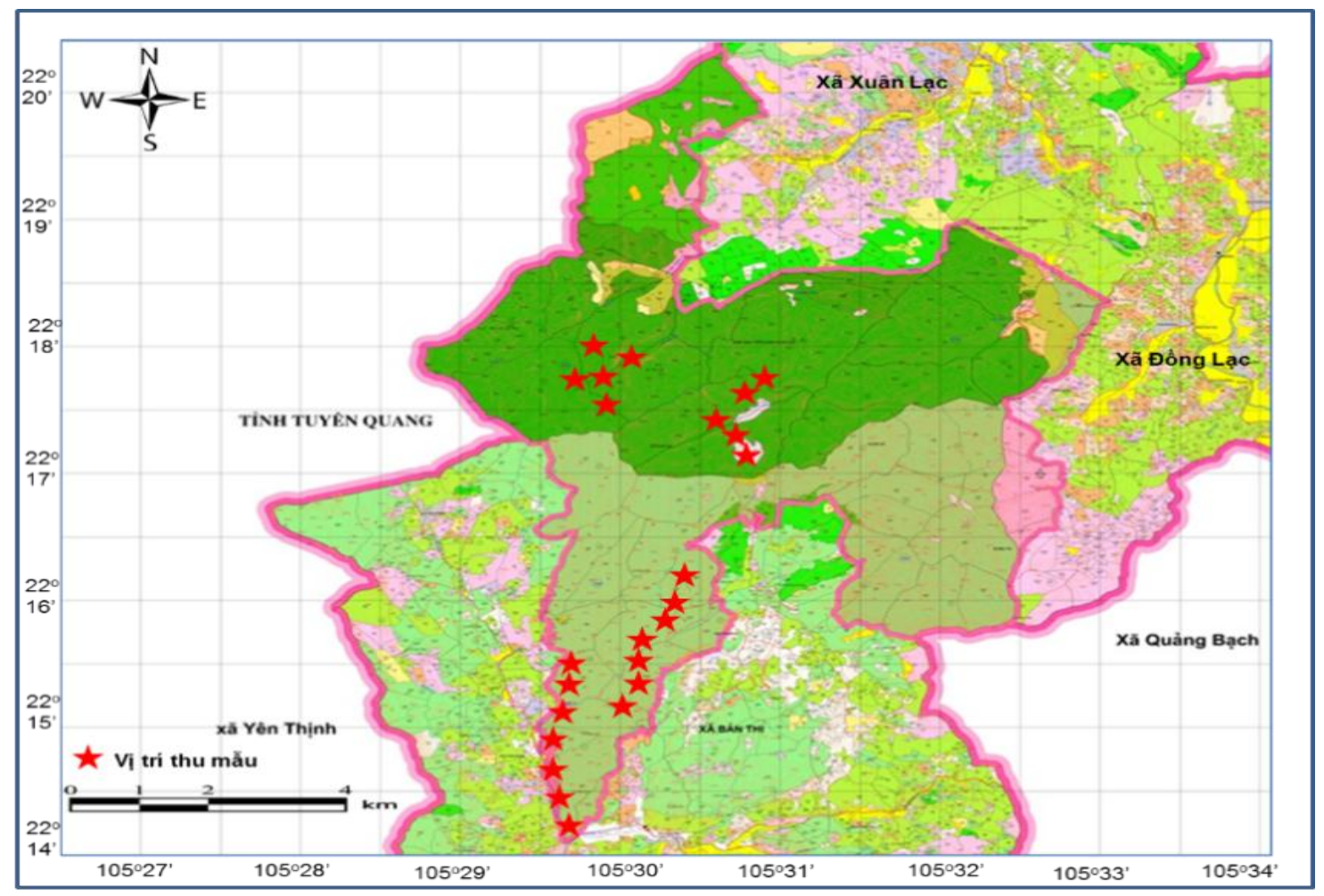

Hình 1. So đồ các điểm khảo sát thu mẫu

\subsection{Phương pháp nghiên cứu}

Ốc cạn được thu theo hướng dẫn của Vermeulen \& Maassen (2003) Thu toàn bộ mẫu ốc cạn hiện diện trong ô tiêu chuẩn (diện tích $1 \mathrm{~m}^{2}$ ). Đối với mẫu có kích thước lớn có thể nhặt bằng tay hoặc dùng panh kẹp để thu mẫu. Đối với các mẫu nhỏ dùng sàng có mắt lưới cỡ $3 \mathrm{~mm}, 5 \mathrm{~mm}, 8 \mathrm{~mm}$ bằng kim loại để sàng các lá mục, bên dưới sàng được hứng bằng tấm nilong sáng màu. Nếu có ốc nhỏ bám dưới lá mục, khi sàng mẫu sẽ rơi xuống và có thể dùng kính lúp cầm tay hoặc nhìn bằng mắt nhặt mẫu.
Các mẫu ốc thu được ở mỗi ô cho vào một túi nilon hoặc một lọ đựng mẫu có đề nhãn. Nhãn ghi các thông tin: Địa điểm, thời gian, toạ độ, sinh cảnh, đặc điểm thảm thực vật, ...

Các loài ốc cạn có thể định loại dựa vào các đặc điểm hình thái của vỏ như: Kích thước, hình dạng, màu sắc, số vòng xoắn, rãnh xoắn, đỉnh vỏ, miệng vỏ, ... được thể hiện qua các số đo hay tỷ lệ của chúng. Ngoài ra, một vài đặc điểm có giá trị tham khảo để định loại như sự phân bố, các khía, hoa văn trên vỏ. Các tài liệu của Dautzenberg và Fischer được dùng chủ yếu cho việc định loại các mẫu thu được. Sắp xếp danh mục các bậc phân loại dựa theo hệ thống của Bouchet và Rocroi (2017). 

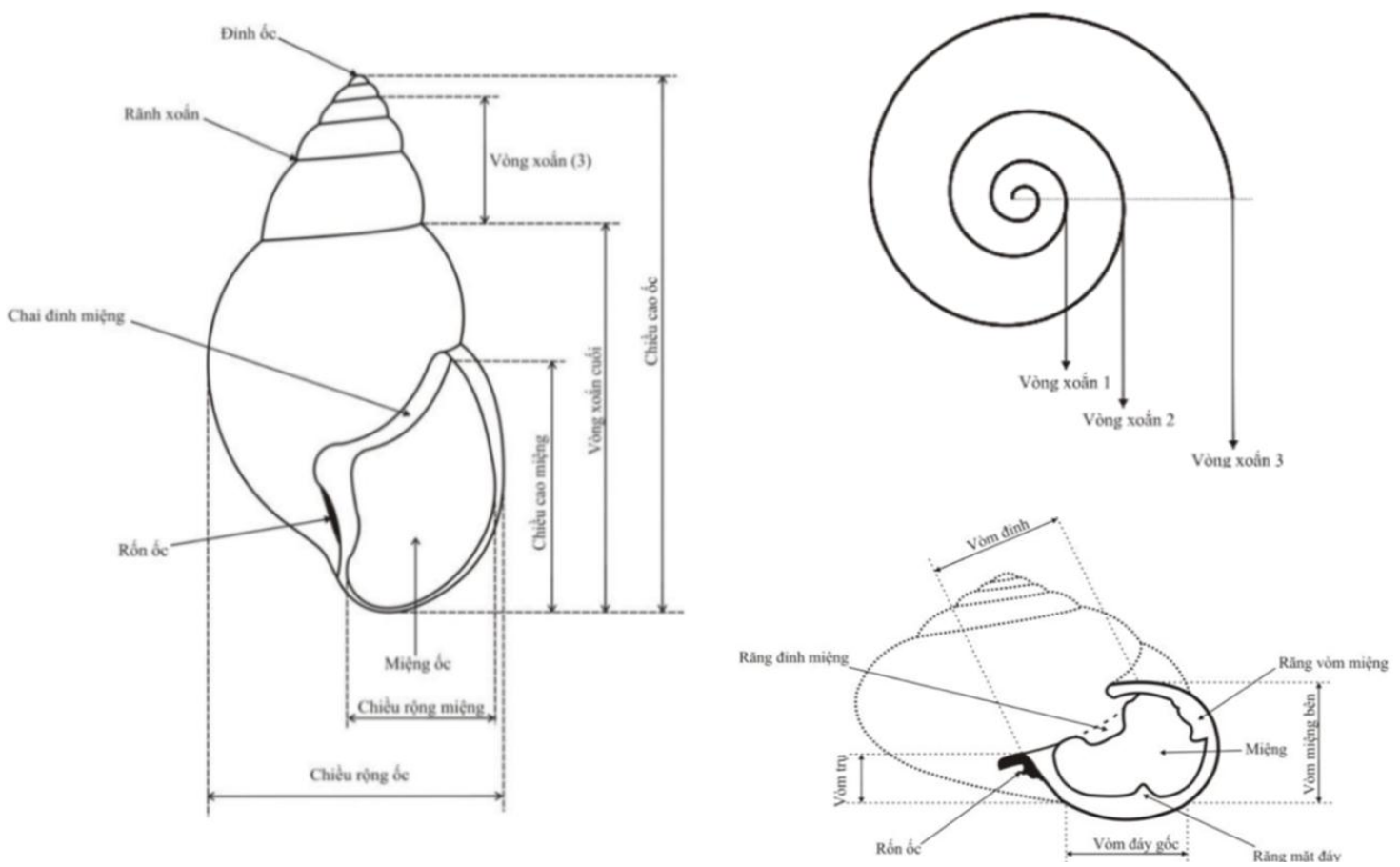

Hình 2. Một số đặc điểm cần phân tích khi định danh ốc cạn

Độ phong phú của loài được tính theo công thức của Kreds $1989(\mathrm{P} \%=(\mathrm{ni} / \Sigma \mathrm{n}) \times 100)[[15]]$. Các mẫu được lưu trữ tại phòng thí nghiệm Động vật học, khoa Sinh học, trường Đại học Sư phạm Đại học Thái Nguyên. Chỉ số tương đồng SI = 2c/a+b. Chỉ số đa dạng Shannon-Weiner (H') (1963) [[19]] được xác định theo công thức sau:

$$
\mathrm{H}^{\prime}=-\sum_{\mathrm{i}=1}^{\mathrm{n}} \frac{\mathrm{ni}}{\sum \mathrm{n}} \log _{2}\left(\frac{\mathrm{ni}}{\sum \mathrm{n}}\right)
$$

Sử dụng phần mềm Excel 2010 để tính toán các chỉ số.

\section{KẾT QUẢ NGHIÊN CỨU VÀ THẢO} LUẬN

\subsection{Thành phần loài ốc cạn ở khu vực} nghiên cứu

Kết quả phân tích về thành phần loài ốc cạn từ các mẫu thu được tại xã Bản Thi và Xuân Lạc thuộc Khu bảo tồn loài và sinh cảnh Nam Xuân Lạc, tỉnh Bắc Kạn đã xác định được 49 loài và phân loài thuộc 34 giống, 12 họ, 4 bộ, 3 phân lớp (bảng 1). Trong đó, phân lớp Heterobranchia đa dạng nhất với 34 loài (chiếm 69,39\%), 8 họ, 2 bộ; phân lớp Neritimorpha kém đa dạng nhất, chỉ có 1 loài, 1 họ, 1 bộ.
Thành phần ốc cạn thuộc phân lớp Caenogastropoda phù hợp với đặc điểm chung của ốc cạn ở các khu vực vùng núi phía Bắc Việt Nam, thường chiếm tỷ lệ khoảng 1/4-1/3 [2, 3], bao gồm 3 họ phổ biến thường gặp như Cyclophoridae, Diplommatinidae và Pupinidae. Các loài ốc thuộc phân lớp Caenogastropoda thường gặp nhiều ở môi trường có khí hậu nóng ẩm, vùng núi đá vôi. So với khu vực tương tự khác như VQG Xuân Sơn (Phú Thọ), Hữu Lũng (Lạng Sơn) cho thấy, mặc dù tỷ lệ chiếm gần $1 / 3$ tổng số loài, nhưng số loài trong phân họ Cyclophorinae cũng đạt tới 5 loài, điều này chứng tỏ môi trường vùng này cũng khá ẩm ướt và được bảo vệ tốt.

Trong các bộ được ghi nhận trong khu vực nghiên cứu, bộ Stylommatophora có thành phần loài đa dạng nhất, với 33 loài (chiếm 67,35\%), 7 họ; bộ Architaenioglossa có 14 loài, 3 họ; hai bộ Cycloneritida và Systellommatophora, mỗi bộ đều chỉ có 1 loài, 1 họ; Trong số 12 họ, họ Camaenidae có số loài nhiều nhất, với 16 loài (chiếm 32,65\%), họ Cyclophoridae có 7 loài, họ Ariophantidae có 6 loài, họ Pupinidae có 5 loài, các họ khác có từ 1 đến 4 loài.

Nhìn chung, thành phần loài ốc cạn khu vực nghiên cứu khá phong phú về các đơn vị phân loại, gặp hầu hết các họ phổ biến ở khu vực Đông Nam Á và Nam Trung Hoa. 
Bảng 1. Thành phần loài ốc cạn tại KVNC

\begin{tabular}{|c|c|c|c|}
\hline TT & $\begin{array}{c}\text { TÊN CÁC TAXON } \\
\text { (Phân lớp, Bộ, Họ, Loài/Phân loài) }\end{array}$ & $\begin{array}{c}\text { Mật độ trung } \\
\text { bình (Cá } \\
\text { thể/ m²) }\end{array}$ & $\begin{array}{c}\text { Độ phong } \\
\text { phú của loài } \\
(\text { pi\% })\end{array}$ \\
\hline $\mathbf{A}$ & PHÂN LỚP NERITIMORPHA & & \\
\hline \multirow[t]{3}{*}{$\mathbf{I}$} & Bộ CYCLONERITIDA & & \\
\hline & Liên họ Helicinoidea & & \\
\hline & 1. Họ Helicinidae Férussac, 1822 & & \\
\hline 1 & Geotrochatella jourdyi Dautzenberg, 1895 & 0.66 & 6.69 \\
\hline $\mathbf{B}$ & PHÂN LỚP CAENOGASTROPODA & & \\
\hline \multirow[t]{4}{*}{ II } & Bộ ARCHITAENIOGLOSSA & & \\
\hline & Liên họ Cyclophoroidea & & \\
\hline & 2. Họ Cyclophoridae Gray, 1847 & & \\
\hline & Phân họ Alycaeinae Blanford, 1864 & & \\
\hline 2 & Dicharax cristatus (Möllendorff, 1886) & 0.03 & 0.30 \\
\hline \multirow[t]{2}{*}{3} & Dioryx messageri (Bavay et Dautzenberg, 1900) & 0.06 & 0.61 \\
\hline & Phân họ Cyclophorinae Gray, 1847 & & \\
\hline 4 & Cyclophorus dorans Mabille, 1887 & 0.23 & 2.33 \\
\hline 5 & Cyclophorus pyrostoma (Möllendorff, 1882) & 0.74 & 7.51 \\
\hline 6 & Cyclotus lubricus (Dautzenberg \& H. Fischer, 1908) & 0.26 & 2.64 \\
\hline 7 & Japonia scissimargo Benson, 1856 & 0.8 & 8.11 \\
\hline \multirow[t]{2}{*}{8} & Scabrina tonkiniana Mabille, 1887 & 0.06 & 0.61 \\
\hline & 3. Họ Diplommatinidae Pfeiffer, 1856 & & \\
\hline 9 & Diplommatina balansai robusta (Bavay et Dautzenberg, 1903) & 0.57 & 5.78 \\
\hline \multirow[t]{2}{*}{10} & Diplommatina triangula T.C. Yen, 1939 & 0.03 & 0.30 \\
\hline & 4. Họ Pupinidae Pfeiffer, 1853 & & \\
\hline 11 & Otopoma blennus Benson, 1856 & 0.23 & 2.33 \\
\hline 12 & Pollicaria mouhoti (Pfeiffer, 1862) & 0.54 & 5.48 \\
\hline 13 & Pollicaria rocherbruni Mabille, 1887 & 0.34 & 3.45 \\
\hline 14 & Pupina judelliana Möllendorff, 1883 & 0.03 & 0.30 \\
\hline 15 & Tyloechus ottonis ottonis Dohrn, 1862 & 0.09 & 0.91 \\
\hline \multirow[t]{2}{*}{$\mathbf{C}$} & PHÂN LỚP HETEROBRANCHIA & & \\
\hline & LIÊN BỘ EUPULMONATA & & \\
\hline \multirow[t]{3}{*}{ III } & Bộ SYSTELLOMMATOPHORA & & \\
\hline & Liên họ Veronicelloidea & & \\
\hline & 5. Họ Veronicellidae Gray, 1840 & & \\
\hline 16 & Laevicaulis alte (Férussac, 1822) & 0.08 & 0.81 \\
\hline \multirow[t]{4}{*}{ IV } & Bộ STYLOMMATOPHORA & & \\
\hline & Liên họ Achatinoidea & & \\
\hline & 6. Họ Achatinidae Swainson, 1840 & & \\
\hline & Phân họ Achatininae Swainson, 1840 & & \\
\hline \multirow[t]{2}{*}{17} & Achatina fulica (Bowdich, 1822) & 0.03 & 0.30 \\
\hline & Phân họ Glessulinae Godwin-Austen, 1920 & & \\
\hline \multirow[t]{2}{*}{18} & Glessula paviei Morlet, 1892 & 0.14 & 1.42 \\
\hline & Phân họ Subulininae Fischer \& Crosse, 1877 & & \\
\hline 19 & Allopeas subula (Crosse et fischer, 1863) & 0.03 & 0.30 \\
\hline 20 & Prosopeas anceyi Pilsbry, 1906 & 0.06 & 0.61 \\
\hline
\end{tabular}




\begin{tabular}{|c|c|c|c|}
\hline TT & $\begin{array}{c}\text { TÊN CÁC TAXON } \\
\text { (Phân lớp, Bộ, Họ, Loài/Phân loài) }\end{array}$ & $\begin{array}{c}\text { Mật độ trung } \\
\text { bình (Cá } \\
\left.\text { thể/ } \mathbf{m}^{2}\right)\end{array}$ & $\begin{array}{c}\text { Độ phong } \\
\text { phú của loài } \\
\text { (pi\%) }\end{array}$ \\
\hline & Liên họ Streptaxoidea & & \\
\hline & 7. Họ Streptaxidae Gray, 1860 & & \\
\hline 21 & Elma messageri (Bavay et Dautzenberg, 1903) & 0.06 & 0.61 \\
\hline \multirow[t]{3}{*}{22} & Haploptychius blaisei (Dautzenberg et Fischer, 1905) & 0.06 & 0.61 \\
\hline & Liên họ Plectopyloidea & & \\
\hline & 8. Họ Plectopylidae Möllendorff, 1898 & & \\
\hline 23 & Plectopylis dautzenbergi Gude, 1901 & 0.11 & 1.12 \\
\hline \multirow[t]{3}{*}{24} & Plectopylis mansuyi Gude, 1907 & 0.06 & 0.61 \\
\hline & Liên họ Clausilioidea & & \\
\hline & 9. Họ Clausiliidae Gray, 1855 & & \\
\hline 25 & Clausilia aborensis Godwin-Austen, 1918 & 0.11 & 1.12 \\
\hline \multirow[t]{3}{*}{26} & Clausilia giardi Fischer, 1898 & 0.23 & 2.33 \\
\hline & Liên họ Arionoidea & & \\
\hline & 10. Họ Philomycidae Gray, 1847 & & \\
\hline \multirow[t]{3}{*}{27} & Meghimatium pictum (Stoliczka, 1873) & 0.15 & 1.52 \\
\hline & Liên họ Helicarionoidea & & \\
\hline & 11. Ho Ariophantidae Godwin-Austen, 1888 & & \\
\hline 28 & Macrochlamys despecta (Mabille, 1887) & 0.31 & 3.14 \\
\hline 29 & Macrochlamys douvillei (Dautzenberg et Fischer, 1905) & 0.03 & 0.30 \\
\hline 30 & Megaustenia balansai (Mabille, 1889) & 0.14 & 1.42 \\
\hline 31 & Megaustenia siamensis (Haines, 1858) & 0.17 & 1.72 \\
\hline 32 & Sivella montana (Möllendorff, 1901) & 0.34 & 3.45 \\
\hline \multirow[t]{4}{*}{33} & Sivella paviei (Morlet, 1884) & 0.06 & 0.61 \\
\hline & Liên họ Helicoidea & & \\
\hline & 12. Họ Camaenidae Pilsbry, 1895 & & \\
\hline & Phân họ Bradybaeninae Pilsbry, 1934 & & \\
\hline 34 & Bradybaena similaris (Férussac, 1821) & 0.09 & 0.91 \\
\hline 35 & Bradybaena jourdyi (Morlet, 1886) & 0.11 & 1.12 \\
\hline \multirow[t]{2}{*}{36} & Chalepotaxis infantilis (Gredler, 1881) & 0.31 & 3.14 \\
\hline & Phân họ Camaeninae Pilsbry, 1895 & & \\
\hline 37 & Chloritis diestalmena (Dautzenberg et Fischer, 1908) & 0.03 & 0.30 \\
\hline 38 & Plectotropis bonnieri (Fischer, 1898) & 0.09 & 0.91 \\
\hline 39 & Plectotropis chondroderma Möllendorff, 1900 & 0.57 & 5.78 \\
\hline 40 & Amphidromus dautzenbergi Fulton, 1899 & 0.11 & 1.12 \\
\hline 41 & Camaena cicatricosa cicatricosa (Müller, 1774) & 0.31 & 3.14 \\
\hline 42 & Camaena contractiva Mabille, 1889 & 0.11 & 1.12 \\
\hline 43 & Camaena hainanensis (Adams, 1870) & 0.23 & 2.33 \\
\hline 44 & Ganesella onestera (Mabille, 1887) & 0.37 & 3.75 \\
\hline 45 & Ganesella oxytropis (Möllendorff, 1901) & 0.11 & 1.12 \\
\hline 46 & Moellendorffia blaisei (Dautzenberg et Fischer, 1905) & 0.09 & 0.91 \\
\hline 47 & Moellendorffia sculptilis (Moellendorff,1884) & 0.14 & 1.42 \\
\hline 48 & Neocepolis cherrieri depressa Dautzenberg \& Fischer, 1908 & 0.26 & 2.64 \\
\hline \multirow[t]{2}{*}{49} & Neocepolis morleti (Dautzenberg \& Hamonville, 1887) & 0.09 & 0.91 \\
\hline & TỔNG & 9.86 & 100 \\
\hline
\end{tabular}




\section{Nhân xét về đô phong phú của loài:}

Các loài đã gặp chủ yếu là các loài phân bố rộng, đã gặp ở hầu hết các khu vực khác trên lãnh thổ Việt Nam như: Bradybaena jourdyi, Bradybaena similaris... Bên cạnh đó, cũng có những loài phân bố hẹp. Trong khu vực nghiên cứu, độ phong phú $(\mathrm{P} \%)$ của các loài có sự khác biệt rõ rệt (bảng 1), cụ thể như sau:

Loài có độ phong phú cao nhất là Japonia scissimargo $(\mathrm{P} \%=8,11 \%)$, thứ hai là loài Cyclophorus pyrostoma $(\mathrm{P} \%=7,51 \%)$, tiếp theo là loài Geotrochatella jourdyi $(\mathrm{P} \%=6,69 \%)$, loài Diplommatina balansai robusta, Plectotropis chondroderma, Pollicaria mouhoti $(\mathrm{P} \%=5,48 \%$ $5,78 \%)$. Các loài còn lại có độ phong phú thấp ( $\mathrm{P} \%<$ $5 \%$ ), thậm chí một số loài có mật độ cá thể rất thấp và độ phong phú cũng rất thấp $(\mathrm{P} \%<1)$.

\section{Đánh giá về đô đa dang của ốc can trong} $\underline{K V N C:}$

Căn cứ vào thành phần loài, mật độ cá thể trung bình của từng loài trong khu vực nghiên cứu, độ đa dạng Shannon-Weiner ( $\left.H^{\prime}\right)$ của ốc cạn trong khu vực này là 3,5 . Với giá trị này, mức độ đa dạng của ốc cạn ở đây được đánh giá là khá cao.

\section{Nhân xét về kích thước các loài:}

Thành phần loài ở Khu bảo tồn thiên nhiên Nam Xuân Lạc, tỉnh Bắc Kạn bao gồm đầy đủ nhóm có kích thước từ bé đến rất lớn:

+ Nhóm có kích thước lớn (lớn hơn 30mm): Gồm 02 loài thuộc họ Cyclophoridae: Cyclophorus dorans, Cyclophorus pyrostoma. 02 loài thuộc họ Ariophantidae gồm: Megaustenia balansai, Megaustenia siamensis. 03 loài thuộc họ Camaenidae gồm: Camaena cicatricosa cicatricosa, Camaena contractiva, Camaena hainanensis.

+ Nhóm có kích thước trung bình (từ $20 \mathrm{~mm}$ 30mm): Gồm 02 loài thuộc họ Pupinidae: Pollicaria mouhoti, Pollicaria rocherbruni. 01 loài thuộc họ
Ariophantidae: Macrochlamys despecta. 03 loài thuộc họ Camaenidae: Amphidromus dautzenbergi, Moellendorffia sculptilis, Neocepolis cherrieri depressa.

+ Nhóm có kích thước bé (từ $5 \mathrm{~mm}-20 \mathrm{~mm}$ ): Gồm 04 loài thuộc họ Cyclophoridae: Cyclotus lubricus, Dioryx messageri, Japonia scissimargo, Scabrina tonkiniana. 02 loài thuộc họ Pupinidae: Otopoma blennus, Tyloechus ottonis ottonis. 01 loài thuộc họ Helicinidae: Geotrochatella jourdyi. 03 loài thuộc họ Ariophantidae: Macrochlamys douvillei, Sivella montana, Sivella paviei. 06 loài thuộc phân họ Bradybaeninae: Bradybaena similaris, Bradybaena jourdyi, Chalepotaxis infantilis, Chloritis diestalmena, Plectotropis bonnieri, Plectotropis chondroderma. 04 loài thuộc họ Camaenidae: Ganesella onestera, Ganesella oxytropis, Moellendorffia blaisei, Neocepolis morleti. 02 loài thuộc họ Clausiliidae: Clausilia aborensis, Clausilia giardi. 01 loài thuộc họ Glessulidae: Glessula paviei. 02 loài thuộc họ Plectopylidae: Plectopylis dautzenbergi, Plectopylis mansuyi. 01 loài thuộc họ Streptaxidae: Haploptychius blaisei.

+ Nhóm có kích thước rất bé (nhỏ hơn $5 \mathrm{~mm}$ ): Gồm các loài: Dicharax cristatus, Dioryx compactus, Diplommatina balansai robusta, Diplommatina triangula, Pupina judelliana, Elma messageri, Allopeas subulla, Prosopeas verona.

\subsection{Các loài ốc cạn có giá trị ở khu vực nghiên cứu}

Qua khảo thực tế tại địa phương, trong số 49 loài ốc cạn ghi nhận ở 2 xã trong Khu bảo tồn loài và sinh cảnh Nam Xuân Lạc huyện Chợ Đồn, tỉnh Bắc Kạn đã xác định 7 loài có giá trị kinh tế. Những loài này được người dân địa phương sử dụng làm thực phẩm, khai thác và bán ở chợ địa phương hoặc bán cho các đầu mối đưa về các thành phố lớn và thủ đô Hà Nội. Hoạt động khai thác nhiều nhất là từ tháng 4 đến tháng 7 hàng năm, đặc biệt sau những trận mưa rào và vào ban đêm, khi các loài ốc cạn bò ra ngoài để kiểm ăn thì việc khai thác ốc núi càng diễn ra thuận lợi (Bảng 2).

Bảng 2. Danh sách các loài ốc cạn có giá trị thực phẩm

\begin{tabular}{|c|c|c|}
\hline TT & \multicolumn{1}{|c|}{ Tên khoa học } & Tên phổ thông \\
\hline & 1. Họ Cyclophoridae Gray, 1847 & \\
\hline 1 & Cyclophorus dorans Mabille, 1887 & Ốc núi to \\
\hline 2 & Cyclophorus pyrostoma (Möllendorff, 1882) & Ốc núi miệng đỏ \\
\hline
\end{tabular}




\begin{tabular}{|c|l|c|}
\hline TT & \multicolumn{1}{|c|}{ Tên khoa học } & Tên phổ thông \\
\hline & \multicolumn{1}{|c|}{ 2. Họ Pupinidae Pfeiffer, 1853 } & \\
\hline 3 & Pollicaria mouhoti (Pfeiffer, 1862) & Ốc nhộng voi \\
\hline 4 & Pollicaria rocherbruni Mabille, 1887 & Ốc nhộng voi \\
\hline & 3. Họ Camaenidae Pilsbry, 1895 & \\
\hline 5 & Camaena cicatricosa cicatricosa (Müller, 1774) & Ốc lưng gù (ốc lạc đà) sần \\
\hline 6 & Camaena contractiva Mabille, 1889 & Ốc lưng gù tròn \\
\hline 7 & Camaena hainanensis (Adams, 1870) & Ốc lưng gù hải nam \\
\hline
\end{tabular}

Mặc dù nhóm ốc cạn chưa được nghiên cứu đầy đủ và chưa có loài nào được đưa vào trong sách đỏ, tuy nhiên với hoạt động khai thác mạnh như hiện nay thì nguồn lợi ốc cạn sẽ ngày càng cạn kiệt, một số loài có thể sẽ bị đe doạ.

\section{KẾT LUẬN}

Kết quả khảo sát về thành phần loài ốc cạn ở 2 xã Xuân Lạc và Bản Thi thuộc khu Bảo tồn loài và sinh cảnh Nam Xuân Lạc, huyện Chợ Đồn, tỉnh Bắc Kạn đã xác định được 49 loài và phân loài thuộc 34 giống, 12 họ, 4 bộ, 3 phân lớp. Trong đó, phân lớp Heterobranchia đa dạng nhất với 34 loài (chiếm 69,39\%); bộ Stylommatophora có thành phần loài đa dạng nhất, với 33 loài (chiếm 67,35\%); họ Camaenidae có số loài nhiều nhất, với 16 loài (chiếm 32,65\%). Thành phần loài ốc cạn khu vực nghiên cứu khá phong phú về các đơn vị phân loại, phù hợp với đặc điểm chung của ốc cạn ở các khu vực vùng núi phía Bắc Việt Nam, gặp hầu hết các họ phổ biến ở khu vực Đông Nam Á và Nam Trung Hoa. Độ đa dạng của ốc cạn ở đây được đánh giá là khá cao, với chỉ số Shannon $H^{\prime}=3,5$.

Kết quả nghiên cứu cũng xác định được 7 loài có giá trị kinh tế. Những loài này được người dân địa phương sử dụng làm thực phẩm. Hoạt động khai thác nhiều nhất là từ tháng 4 đến tháng 7 hàng năm. Với hoạt động khai thác mạnh như hiện nay thì nguồn lợi ốc cạn sẽ ngày càng cạn kiệt, một số loài có thể sẽ bị đe doạ.

\section{TÀI LIỆU THAM KHẢO}

1. Report on planning for conservation and sustainable development of Nam Xuan Lac Species and Habitat conservation, Cho Don district, Bac Kan province for the period 2013-2020. Forest Protection Department, Department of Agriculture and Rural Development of Bac Kan Province (2013).

2. Do Van Nhuong, Hoang Ngoc Khac, Khong Thuy Anh (2010), Initial data on snail (Gastropoda) in village Du, Xuan Son National Park, Phu Tho province. Journal of Biology, 32 (1): p. 13-16.

3. Do Van Nhuong, Nguyen Thi Lan Phuong, Hoang Ngoc Khac (2011). Initial data on snail (Gastropoda) in Quyet Thang commune, Lang Son province. National Scientific Conference on Ecology and Biological Resources, the IV: p. 797-800.

4. Vu Tien Thinh (2013). Composition of rare and precious fauna species in Nam Xuan Lac species and habitat reserve, Bac Kan province.The 5th National Scientific Conference on Ecology and Biological Resources: p. 735-740.

5. Tran Thanh Tung (2019). Diversity of amphibians and reptiles in Nam Xuan Lac Species and Habitat Conservation Area, Cho Don District, Bac Kan Province. Journal of Science and Technology, Thai Nguyen University, vol.207 (14): P. 73-78. 


\section{Species composition of land snails in ban thi and Xuan Lac commune \\ belong to Nam Xuan Lac species and landscape conservation area, Cho Don district, Bac Kan province}

Hoang Ngoc Khac, Tran Thinh, Nguyen Thanh Binh

\begin{tabular}{l}
\hline Article info \\
\hline Recieved: \\
8/6/2020 \\
Accepted: \\
12/8/2020 \\
\hline
\end{tabular}

Keywords:

Land snail, Gastropoda, Xuan Lac, Ban Thi, Cho Don, Bac Kan.

\begin{abstract}
Nam Xuan Lac Species and Habitat Conservation Area, Cho Don District, Bac Kan Province is one of the typical areas of limestone mountains in the North of Vietnam with low-impact natural forests and rugged topography to create conditions for many species of plants and animals to live. Survey results on the species composition of land snails in Xuan Lac and Ban Thi communes of Nam Xuan Lac species and habitat conservation area have identified 49 species and subspecies of 34 genera, 12 families, 4 orders, 3 subclasses. In which, the Heterobranchia subclass is the most diverse with 34 species (accounting for 69.39\%); Stylommatophora order has the most diverse species composition, with 33 species (accounting for 67.35\%); family Camaenidae has the largest number of species with 16 species (accounting for 32.65\%). The species composition of the land snails in the study is quite rich in taxonomy, consistent with the general characteristics of the land snails fauna in the mountainous areas in the northern of Vietnam, and in the South East Asia and Southern China. The diversity of land snails is considered quite high with Shannon index $\mathrm{H}^{\prime \prime}=3.5$. The study results also identified 7 species of economic value. These species are used by the local people for food. Exploitating activities are most from April to July each year. With the current strong exploitation activities, the resources of land snails will be increasingly exhausted, and some species may be threatened.
\end{abstract}

